\title{
Anemia in chronic kidney disease
}

1. Universidade Federal de São Paulo, Disciplina de Nefrologia, São Paulo, SP, Brasil. 2. Hospital do Rim, Divisão de Nefrologia, São Paulo, SP, Brasil.

http://dx.doi.org/10.1590/1806-9282.66.S1.55

KEYWORDS: Anemia; chronic kidney disease (CKD); functional iron deficiency; erythropoiesis- stimulating agentes (ESA); hypoxia-inducible fator (HIF) stabilizers.

\section{INTRODUCTION}

Anemia, defined as hemoglobin $(\mathrm{Hb}) \leq 12 \mathrm{~g} / \mathrm{dL}$ in women and $\mathrm{Hb} \leq 13 \mathrm{~g} / \mathrm{dL}$ in men ${ }^{1}$, was first linked to chronic kidney disease (CKD) in 1836 by Richard Bright $^{2}$. This condition is highly prevalent, although treatable, whose frequency increases in the more advanced stages of the disease. It can be found in more than $50 \%$ of patients with the diagnosis of CKD in stages 4 and $5^{3}$ and appears earlier in individuals with diabetes mellitus (DM) ${ }^{4}$.

Anemia in CKD is typically normocytic, normochromic, and hypoproliferative. The discovery of a factor produced in the renal cortex and responsible for stimulating erythropoiesis, later identified as erythropoietin (EPO), led to the hypothesis that its deficiency could be the main cause of anemia in CKD patients ${ }^{5}$.

\section{PHYSIOPATHOLOGY}

The erythropoietic system is responsible for maintaining the balance in the supply of red blood cells, thus, ensuring an adequate tissue oxygenation ${ }^{4}$. To maintain this balance, the senescent erythrocytes are replaced by new cells. Hypoxia plays an important role in stimulating erythrocyte production through its interaction with the HIF (hypoxia-inducible factor) system. The HIF is a heterodimer consisting of two subunits: alpha and beta. The production of HIF-alpha is continuous; however, its degradation occurs in the absence of tissue hypoxia. On the opposite situation, alpha and beta subunits join and bind in the nucleus of the cell, a DNA sequence called hypoxia-responsive elements. Thus, the production of erythropoietin is stimulated.

Erythropoietin, in turn, is a molecule of 165 amino acids and 4 chains of carbohydrates. Pro duced mainly in the interstitial cells of the renal cortex, with the reduction of glomerular filtration, the hepatic production increases significantly. The half-life of erythropoietin is 5 to 12 hours, and it acts as a true hormone that binds to receptors of bone marrow cells to produce erythrocytes ${ }^{4-6}$.

Although the reduction in the production of erythropoietin significantly contributes to anemia in CKD, it is not the only cause. Iron deficiency is common, and it is estimated that patients on hemodialysis have an iron loss of around 1 to 3 grams per year ${ }^{7}$. Even in patients not receiving dialysis, low levels of iron are often found ${ }^{4}$. Frequent phlebotomies, blood loss in the hemodialysis apparatus, and impairment in its absorption may explain this finding ${ }^{5}$. The beginning of treatment with erythropoietin analogs showed how common iron deficiency is among CKD patients ${ }^{5.8}$. 
Iron deficiency often occurs as a functional deficiency and is characterized by a low transferrin saturation index (TSI) and normal or increased ferritin. Ferritin can be increased in the presence of inflammation, infection, liver disease, and malignancy ${ }^{2}$. Thus, its high levels may not reflect stored iron. The regulation and maintenance of systemic iron homeostasis also depend on hepcidin ${ }^{9.10}$. Produced in the liver, it induces the degradation of ferroportin in duodenal enterocytes, hepatocytes, and macrophages, which prevents proper absorption and use of iron. Inflammatory cytokines are capable of inducing the transcription of hepcidin ${ }^{5.6}$, and there is evidence of its increase in patients with $\mathrm{CKD}^{5}$.

Anemia in CKD is, therefore, a process with multiple causes, which includes mainly the deficiency of erythropoietin, reduction in the life span of erythrocytes (of poorly defined etiology), and changes in the homeostasis of iron.

\section{CLINICAL CONSEQUENCES}

Anemia is associated with several symptoms that lead to reduced quality of life, such as fatigue, dyspnea, insomnia, and headache. It is also related to reduced cognitive capacity. However, these symptoms are nonspecific and could be, in patients with CKD, a consequence of uremia4. Since symptoms develop gradually, many patients do not report complaints spontaneously; however, when actively questioned, they may report limitations in their usual activities.

In addition, anemia is associated with left ventricular hypertrophy (LVH), an increased number of hospitalizations, a possible progression of CKD, and death ${ }^{11.12}$. The increase in mortality occurs mainly when $\mathrm{Hb} \leq 8 \mathrm{~g} / \mathrm{dL}^{13}$.

In relation to $\mathrm{LVH}$, some studies have associated lower levels of hemoglobin, especially $\mathrm{Hb}<7.7 \mathrm{~g} / \mathrm{dL}$, with the increase of left ventricular mass. Silberberg et al. ${ }^{14}$ described that for each $1 \mathrm{~g} / \mathrm{dL}$ reduction of hemoglobin, there was an increase of $6 \%$ in the incidence of LVH.

The hypothesis that anemia may be related to the progression of CKD emerged from experimental studies. Since there is a direct relationship between the concentration of hemoglobin and tissue oxygenation, the presence of anemia could lead to hypoxia of the tubular cells, which, in turn, would contribute to the progression of the tubulointerstitial injury present in CKD. Furthermore, erythrocytes are described as an antioxidant component, and its reduction could be associated with increased oxidative stress ${ }^{15}$. In a post hoc analysis of the RENAAL study ${ }^{16}$, the initial concentration of hemoglobin was an independent predictor of renal outcome. Even slightly decreased values were related to the risk of disease progression. However, it is important to remember that the prevalence of anemia increases with the progression of CKD, and, therefore, a cause-effect relationship cannot be established. In opposition to the RENAAL study, other observational and intervention studies ${ }^{17.18} \mathrm{did}$ not find a significant relationship between the evolution of the CKD and hemoglobin concentrations.

Before the start of treatment with erythropoietin analogs, lower hemoglobin levels were common among patients on dialysis- which exposed them to the risk of multiple blood transfusions and reduced functionality 11,12,17.

\section{DIAGNOSIS AND TREATMENT}

The presence of anemia in CKD does not imply that treatment with erythropoietin analogs should necessarily be initiated. It is recommended, however, to investigate its cause even with values slightly below normal $(\mathrm{Hb}<12 \mathrm{~g} / \mathrm{dL})^{4}$.

The initial assessment is similar to that in other populations, although an emphasis on iron deficiency is suggested. It is common to find high levels of ferritin, which can reflect inflammation and does not exclude iron deficiency. TSI, the level of circulating iron, should also be analyzed. However, none of these two parameters, alone, can predict the actual iron status in CKD patients. When analyzed together and according to their fall or rise tendency, it is possible to predict response to treatment.

The dosage of erythropoietin should not be performed since its deficiency is relative. Tests results would not help in the diagnosis or treatment management ${ }^{4}$.

In 1989, the approval of the first erythropoietin analog revolutionized treatment of anemia in CKD. Until then, patients were treated only when very symptomatic, with multiple blood transfusions ${ }^{8}$. The transfusions exposed them to the risk of infections, transfusion reactions and, in addition, often prevent renal transplantation.

Currently, the use of erythropoietin analogs is widespread. However, before starting these erythropoiesis-stimulating agents (ESA), iron deficiency must 
be investigated. Iron replacement can be done orally or parenterally. The first route is used for most patients not receiving dialysis or undergoing peritoneal dialysis since there is a concern to preserve vascular access. However, in patients undergoing hemodialysis, the oral route presents reduced effectiveness ${ }^{19}$.

An exception is ferric citrate supplementation, which is effective even for patients on dialysis.

Parenteral iron, on the other hand, presents excellent effectiveness and is the treatment choice for patients undergoing hemodialysis. Iron infusion can lead to hypotension or hypersensitivity reactions, although it is quite safe $\mathrm{e}^{20}$.

The doses recommended for iron replacement depend, among other factors, on the stage of the disease.

The recommendation by the Brazilian Society of Nephrology is that patients with CKD stages 1 and 2 should maintain the same levels of ferritin and TSI as the general population ${ }^{21}$. For patients in stage 3, 4 , and 5 who are not on dialysis, serum ferritin and TSI should be kept higher than $100 \mathrm{ng} / \mathrm{mL}$ and $20 \%$, respectively. In dialysis patients, ferritin levels should remain over $200 \mathrm{ng} / \mathrm{mL}$ and $\mathrm{TSI}>20 \%$. In the same way, the interruption of iron replacement is considered when ferritin $>500 \mathrm{ng} / \mathrm{mL}$ and IST $>30 \%$. Iron therapy should be suspended in the presence of active systemic infection ${ }^{20}$.

In 2018, the PIVOTAL study ${ }^{21}$ showed that higher doses of iron might be associated with a lower risk of cardiovascular events and reduced doses of ESA without an increase in the risk of infections. The beginning of treatment with erythropoietin analogs should occur, ideally, when iron deficiency is corrected.

The first erythropoietin analog used was epoetin alfa. Subsequently, darbepoetin was also approved. Both can be administred subcutaneously or parenterally. The use of erythropoietin analogs is not devoid of risks. It is important that blood pressures is controlled ${ }^{4}$. It should be avoided in the presence of active neoplasia, especially when cure is the anticipated outcome, and it is recommended to use with great cautionin patients with previous stroke or malignancy ${ }^{19}$.

After initiating treatment, an increase of hemoglobin at around $1 \mathrm{~g} / \mathrm{dL}$ is expected in the first month. In case of elevations above $1 \mathrm{~g} / \mathrm{dL}$ in two weeks, a dose reduction of $25-50 \%$ is recommended.

The optimal level of hemoglobin is still a controversial issue. Initial studies sought to correct anemia to maintain hemoglobin values similar to the general population. However, two large randomized trials $^{1722}$ showed more cardiovascular events and a lack of improvement in the quality of life when the hemoglobin level was completely corrected. It has been questioned whether this increase in adverse events is related to the higher dose of erythropoietin analogs, and not to the hemoglobin levels reached ${ }^{23}$.

The use of erythropoietin analogs has a clear benefit in patients with $\mathrm{Hb}<10 \mathrm{~g} / \mathrm{dL}$ and increased risk when $\mathrm{Hb}>13 \mathrm{~g} / \mathrm{dL}$. The recommendation to maintain a target of Hb between 10 and $11.5 \mathrm{~g} / \mathrm{dL}$ seems advisable to achieve the benefits of treatment without increased risks ${ }^{4}$.

Recently, a new drug class (the HIF stabilizers) has been proposed for the treatment of anemia in CKD patients ${ }^{6}$. This medication acts through the enzymatic inhibition of prolyl-hydroxylase, leading to the stabilization of HIF factor. The HIF, as mentioned, is a determinant factor in the physiological response to tissue hypoxia. The stabilization of HIF stimulates the endogenous production of erythropoietin. However, its levels are lower than with the use of EPO analogs. This consistent, though less pronounced, increase can be related to a lower risk of cardiovascular events or access thrombosis than those attributed to EPO analogs. Besides stimulating the production of EPO, HIF stabilizers are involved in the iron metabolism. They act reducing the levels of hepcidin, which leads to improved intestinal absorption, as well as increased release of iron from macrophages to transferrin. An additional advantage of HIF stabilizers is its oral administration.

Two phase-3 studies on the use of Roxadustat, a second-generation HIF stabilizer, have been published ${ }^{24.25}$. One of them showed the superiority of Roxadustat in the treatment of anemia in patients not receiving dialysis when compared to a placebo. The other highlighted the non-inferiority of this medication compared to epoetin alfa in patients undergoing dialysis. As additional effects, they found a reduction of hepcidin and total cholesterol, LDL, and triglycerides in patients who used the HIF stabilizer. Hyperkalemia was also more common with the use of Roxadustat.

This new drug option leads to questions regarding the proposed treatment for anemia in CKD. Further studies are needed to ensure that long-term adverse events are evaluated. In addition, it raises the question of whether HIF stabilizers could normalize the hemoglobin level of patients without the risks associated with erythropoietin analogs. 
PALAVRAS-CHAVE: Anemia. Insuficiência renal crônica. Deficiência de ferro.

\section{REFERENCES}

1. DeMaeyer $\mathrm{E}$, Adiels-Tegman $\mathrm{M}$. The prevalence of anaemia in the world. World Health Stat Q. 1985;38(3):302-16.

2. Bright R. Cases and observations: illustrative of renal disease accompanied by the secretion of albuminous urine. Guys Hosp Rep. 1836;1:338.

3. Stauffer ME, Fan T. Prevalence of anemia in chronic kidney disease in the United States. PLoS One. 2014;9(1):e84943.

4. Fishbane S, Spinowitz B. Update on anemia in ESRD and earlier stages of CKD: core curriculum 2018. Am J Kidney Dis. 2018;71(3):423-35.

5. Babitt JL, Lin HY. Mechanisms of anemia in CKD. J Am Soc Nephrol. 2012;23(10):1631-4.

6. Gupta N, Wish |B. Hypoxia-inducible factor prolyl hydroxylase inhibitors: a potential new treatment for anemia in patients with CKD. Am J Kidney Dis. 2017;69(6):815-26.

7. KDOQI; National Kidney Foundation. II. Clinical practice guidelines and clinical practice recommendations for anemia in chronic kidney disease in adults. Am J Kidney Dis. 2006;47(5 Suppl 3):S16-85.

8. Kaplan J. Roxadustat and anemia of chronic kidney disease. N Engl | Med. 2019;381(11):1070-2.

9. Krause A, Neitz S, Mägert HJ, Schulz A, Forssmann WG, Schulz-Knappe $P$, et al. LEAP-1, a novel highly disulfide-bonded human peptide, exhibits antimicrobial activity. FEBS Lett. 2000;480(2-3):147-50.

10. Pigeon C, Ilyin G, Courselaud B, Leroyer P, Turlin B, Brissot P, et al. A new mouse liver-specific gene, encoding a protein homologous to human antimicrobial peptide hepcidin, is overexpressed during iron overload. | Biol Chem. 2001:276(11):7811-9.

11. Nissenson AR, Goodnough LT, Dubois RW. Anemia: not just an innocent bystander? Arch Intern Med. 2003;163(12):1400-4.

12. Sarnak MI, Tighiouart H, Manjunath G, MacLeod B, Griffith |, Salem D, et al. Anemia as a risk factor for cardiovascular disease in The Atherosclerosis Risk in Communities (ARIC) study. J Am Coll Cardiol. 2002;40(1):27-33.

13. Ma IZ, Ebben J, Xia H, Collins AJ. Hematocrit level and associated mortality in hemodialysis patients. | Am Soc Nephrol. 1999;10(3):610-9.
14. Silberberg JS, Rahal DP, Patton DR, Sniderman AD. Role of anemia in the pathogenesis of left ventricular hypertrophy in end-stage renal disease. Am | Cardiol. 1989;64(3):222-4

15. Rossert J, Froissart M. Role of anemia in progression of chronic kidney disease. Semin Nephrol. 2006;26(4):283-9.

16. Keane WF, Brenner BM, de Zeeuw D, Grunfeld JP, McGill J, Mitch WE, et al.; RENAAL Study Investigators. The risk of developing end-stage renal disease in patients with type 2 diabetes and nephropathy: the RENAAL study. Kidney Int. 2003;63(4):1499-507.

17. Pfeffer MA, Burdmann EA, Chen CY, Cooper ME, de Zeeuw D, Eckardt KU, et al; TREAT Investigators. A trial of darbepoetin alfa in type 2 diabetes and chronic kidney disease. N Engl J Med. 2009;361(21):2019-32.

18. Tótoli $C$, Carvalho AB, Ammirati AL, Draibe SA, Canziani ME. Associated factors related to chronic kidney disease progression in elderly patients. PLoS One. 2019;14(7):e0219956.

19. KDIGO. Clinical practice guideline for anemia in chronic kidney disease. Kidney Int Suppl. 2012;2(4):283-335.

20. Abensur H, Castro MC. Iron supplementation in anemia treatment. J Bras Nefrol. 2014;36(1 Suppl 1):15-8.

21. MacDougall IC, White C, Anker SD, Bhandari S, Farrington K, Kalra PA, et al; PIVOTAL Investigators and Committees. Intravenous iron in patients undergoing maintenance hemodialysis. N Engl J Med. 2019;380(5):447-58

22. Singh AK, Szczech L, Tang KL, Barnhart H, Sapp S, Wolfson M, et al; CHOIR Investigators. Correction of anemia with epoetin alfa in chronic kidney disease. N Engl | Med. 2006;355(20):2085-98

23. Solomon SD, Uno H, Lewis EF, Eckardt KU, Lin |, Burdmann EA, et al; Trial to Reduce Cardiovascular Events with Aranesp Therapy (TREAT) Investigators. Erythropoietic response and outcomes in kidney disease and type 2 diabetes. N Engl J Med. 2010;363(12):1146-55.

24. Chen N, Hao C, Liu BC, Lin H, Wang C, Xing C, et al. Roxadustat treatment for anemia in patients undergoing long-term dialysis. $\mathrm{N}$ Engl J Med. 2019;381(11):1011-22.

25. Chen N, Hao C, Peng X, Lin H, Yin A, Hao L, et al. Roxadustat for anemia in patients with kidney disease not receiving dialysis. N Engl J Med. 2019;381(11):1001-10 